Article

\title{
Entropy Based Pythagorean Probabilistic Hesitant Fuzzy Decision Making Technique and Its Application for Fog-Haze Factor Assessment Problem
}

\author{
Bushra Batool ${ }^{1}$, Mumtaz Ahmad ${ }^{1}$, Saleem Abdullah ${ }^{2}{ }^{\circ}$, Shahzaib Ashraf ${ }^{2}{ }^{(D)}$ and \\ Ronnason Chinram ${ }^{3, *}$ (D) \\ 1 Department of Mathematics, University of Sargodha, Sargodha 40100, Pakistan; \\ bushra.batool@uos.edu.pk (B.B.); mumtaz.ahmad@uos.edu.pk (M.A.) \\ 2 Department of Mathematics, Abdul Wali Khan University, Mardan 23200, Pakistan; \\ saleemabdullah@awkum.edu.pk (S.A.); shahzaibashraf@awkum.edu.pk (S.A.) \\ 3 Algebra and Applications Research Unit, Department of Mathematics and Statistics, Faculty of Science, \\ Prince of Songkla University, Hat Yai, Songkhla 90110, Thailand \\ * Correspondence: ronnason.c@psu.ac.th
}

Received: 4 February 2020; Accepted: 5 March 2020; Published: 11 March 2020

\begin{abstract}
The Pythagorean probabilistic hesitant fuzzy set (PyPHFS) is an effective, generalized and powerful tool for expressing fuzzy information. It can cover more complex and more hesitant fuzzy evaluation information. Therefore, based on the advantages of PyPHFSs, this paper presents a new extended fuzzy TOPSIS method for dealing with uncertainty in the form of PyPHFS in real life problems. The paper is divided into three main parts. Firstly, the novel Pythagorean probabilistic hesitant fuzzy entropy measure is established using generalized distance measure under PyPHFS information to find out the unknown weights information of the attributes. The second part consists of the algorithm sets of the TOPSIS technique under PyPHFS environment, where the weights of criteria are completely unknown. Finally, in order to verify the efficiency and superiority of the proposed method, this paper applies some practical examples of the selection of the most critical fog-haze influence factor and makes a detailed comparison with other existing methods.
\end{abstract}

Keywords: Pythagorean probabilistic hesitant fuzzy set; extended TOPSIS technique; decision making problem

\section{Introduction}

In the 21st century, with the rapid economic and social development and the acceleration of industrialization, environmental problems, especially air pollution, have become increasingly severe restricting the economic development of many countries and threatening human health. The continued rise in fossil fuel consumption and emissions of contaminants releases a large amount of particulate matter (PM), which raises concentration of PM, reduces visibility and deteriorates air quality [1]. It is easy to cause fog-haze weather under certain meteorological conditions. Fog-haze is a serious threat to the health of people's respiratory systems, and it is reported that more than 3 million people worldwide die each year from air pollution (mainly from PM) [2]. Hence, studying the issue of the key influence factor of fog-haze weather is meaningful. However, due to the rapid growth of the social economy and the limitation of experts' professional knowledge and cognitive ability, it is somewhat challenging for a single expert to provide comprehensive evaluation information in the face of complex problems with fog-haze weather influencing factors. Thus, it is more reasonable that a group of experts use the comprehensive intelligence, cross-disciplinary knowledge and skills to evaluate the complex influence factors of fog-haze weather collaboratively. 
Real life decision making problems are too complex and challenging due to the presence of different kinds of uncertainties and vagueness in the information data. In 1965, Zadeh [3] proposed the theory of fuzzy sets to model uncertain/vague information effectively. After the pioneering work of Zadeh [3], many generalizations and extensions of fuzzy sets (FSs) have been proposed by researchers and applied in a wide range of application areas. Intuitionistic fuzzy set (IFS), introduced by Atanassov [4], is one of the most significant extensions of the fuzzy set that has been extensively studied and implemented in different disciplines. Over the past thirty years, intuitionistic fuzzy set theory has been successfully employed to solve many problems connected to real life situations such as decision making [5].

Yager [6-8] models Pythagorean fuzzy set (PyFS) as a generalization of IFS, with the constraint that the square sum of positive and negative membership degrees is less than or equal to one. We can say that the space of all intuitionistic membership values is also Pythagorean membership values, but the converse is not true. For example, in an environment where the positive membership value is 0.6 and the negative membership value is 0.5 , we cannot use IFSs because the sum of their membership values exceeds one. So, in this situation we use PyFSs to deal with the decision making problems. As a result, PyFS is stronger than IFSs to make a pact of ambiguity in daily life problems.

Frequently, hesitancy occurs everywhere in our universe. It is difficult to choose one of the best alternatives with the same features in real life. Due to vagueness and hesitancy in the data, experts are having complications in decision making. To overcome the hesitancy, Torra [9] proposed the notion of hesitant fuzzy set (HFS). After that, the enhanced form of hesitating fuzzy sets, the Pythagorean hesitant fuzzy set was proposed by Khan et al. [10]. Overhead notions can be used to determine randomness in an efficient way. Nevertheless, the above frameworks are not capable of dealing with situations in which the rejection of a specialist plays a crucial role in the decision making process. For instance, a board of five proficients is considered to choose the best aspirant in the staffing procedure and three of them rejected to deliver any decision. Although assessing the information by means of the existing tactics, the number of decision makers is vigilant to be three rather than five, i.e., the rejected proficients are totally overlooked and the decision is enclosed by means of the preferences specified by the three proficients only. It causes a significant loss of data and may lead to insufficient grades. To tackle such cases, $\mathrm{Xu}$ and $\mathrm{Zhu}$ [11] sustained a new notion named probabilistic hesitant fuzzy sets (PHFSs). The entropy is a quantitative evaluation of randomness between fuzzy sets. Termini and Luca [12] first developed the construction properties for entropy of fuzzy sets using Shannon's probability entropy. Furthermore, some researchers [13-16] corroborated some generalized entropy measures for IFSs.

Decision making is a significant part of the real world of human beings. With the unceasing development of human beings', real-world decision making challenges are becoming very complicated. There are often numerous aspects that have an immediate effect on the outcome of decision making problems. Such dimensions are often limited to each other and sometimes equally connected. As a consequence, the specialist must understand these things and their relationship in order to solve these decision making problems. It is a stimulating effort to make a pact with these multiattribute decision making (MADM) problems and then to make a good deal between attributes. Clearly, different attributes play an important role in choosing the best alternative between the given options, so different types of aggregation operators are used to calculate the data to characterize the DM setting. Xu [17] proposed some weighted averaging Aggregation Operators (AOs) for IFSs. Wang and Li [18] developed decision making with distance and cosine similarity measures for intuitionistic hesitant fuzzy sets (IHFSs). For instance, a complete review of the different methodologies to deal with vagueness in MADM problems is given in [19-25]. Meng and Chen [26] proposed correlation coefficients of hesitant fuzzy sets and their application based on fuzzy neasures. Garg [27] developed hesitant Pythagorean fuzzy Maclaurin symmetric mean operators and their applications to multiattribute decision making process. Zhao et al. [28] presented group decision making with dual hesitant fuzzy preference relations. Farhadinia and Xu [29] proposed distance and aggregation based 
methodologies for hesitant fuzzy decision making. Arora and Garg [30] presented a robust correlation coefficient measure of dual hesitant fuzzy soft sets and their application in decision making. In [31-34] authors proposed some other types of methodologies under the HFSs to resolve the DM problems. Yue [35] proposed an avoiding information loss approach to group decision making.

Zhang [36] developed an innovative tactic based on similarity measure for Pythagorean fuzzy multicriteria group decision making. Ren et al. [37] considered Pythagorean fuzzy TODIM tactic to multicriteria decision making. Yang et al. [38] developed Pythagorean fuzzy Choquet integral based MABAC method for multiple attribute group decision making. A hierarchical QUALIFLEX tactic is given by Zhang [39]. Pythagorean fuzzy environment measures are developed by Peng et al. [40]. Later on, generalized Pythagorean fuzzy Bonferroni mean aggregation operators are developed by Zhang et al. [41]. Liang et al. [42] generalized TOPSIS to hesitant Pythagorean fuzzy sets. P'erezDom'inguez et al. [43] developed MOORA for Pythagorean fuzzy information. Lately, Xue et al. [44] presented Pythagorean fuzzy LINMAP method based on the entropy for railway project investment decision making. Later on, Meng et al. [45] developed a tactic to interval-valued hesitant fuzzy multiattribute group decision making under extended Shapley-Choquet integral. Guleria et al. [46] presented Pythagorean fuzzy $(R, S)$-norm environment measure for multicriteria decision making problem. Moreover, Yang et al. [47] presented distance and similarity measures for hesitant fuzzy information under Hausdorff metric with applications to multicriteria decision making. Shannon [48] developed entropy in a mathematical theory of communication to determine weights of attributes. Entropy for hesitant fuzzy information under Hausdorff metric with structure of hesitant fuzzy TOPSIS was given by Yang [49].

The TOPSIS is an effective information evaluation tool, which was first given by Hwang and Yoon [50]; it is known as the approximate ideal solution. It seeks the optimal solution according to the relative closeness based on their distances from the positive ideal solution (PIS) and the negative ideal solution (NIS), so as to satisfy the nearest distance from PIS and the farthest distance from NIS. This evaluation method can effectively avoid the distortion of decision information and ensure the validity and accuracy of decision results by directly calculating the distance between PIS and NIS and ranking them accordingly. Compared with ELECTRE method, VIKOR method and other traditional methods, TOPSIS method is simple, and easy to understand and calculate, so it has been widely studied and applied by a large number of scholars. With the emergence of the form of fuzzy information, the TOPSIS method has been widely used in fuzzy environment. TOPSIS firstly prolonged the fuzzy information for resolving decision making problems by [51]. Chen [51] also presented some extensions of the TOPSIS for group decision making under a fuzzy environment.

In the recent era, different authors offered TOPSIS in different fuzzy information: like, Boran et al. [52] find out the best supplier with TOPSIS method by using the intuitionistic fuzzy information. Chen et al. [53] proposed the TOPSIS technique using interval-valued fuzzy information and also discussed the experimental analysis of the proposed technique. Li [54] presented the TOPSIS-based nonlinear-programming methodology for multiattribute decision making with interval-valued intuitionistic fuzzy sets to deal with the uncertainty in real life decision problems. Park et al. [55] introduced the TOPSIS model for decision making problems under interval-valued intuitionistic fuzzy environment. Cables et al. [56] established the TOPSIS decision making approach for linguistic variables. $\mathrm{Xu}$ [57] introduced the TOPSIS technique with incomplete weight information under hesitant fuzzy environment. Beg and Rashid [58] established the TOPSIS model for hesitant fuzzy linguistic term sets to deal with the uncertainty in real life complex problems. Khan et al. [59] proposed the Dombi based aggregation operators for Pythagorean fuzzy information. Biswas and Sarkar [60] established the Pythagorean fuzzy TOPSIS method with unknown weight information through entropy measure for Pythagorean fuzzy information. Barukab et al. [61] introduced the extended fuzzy TOPSIS method based on entropy measure under spherical fuzzy information.

Although there are many research results in applying the fuzzy TOPSIS method to solve MADM problems, the form of decision information used by these methods is too old and limited and cannot 
effectively handle current complex decision environments. Moreover, no matter what aggregation technology in fuzzy TOPSIS method we use, it may cause distortion of decision information. In addition, for decision making problems, sometimes we cannot give the weight of attributes directly and accurately, and some experts may give a too high or too low attribute evaluation value because of personal bias. In addition, the relative closeness of the traditional TOPSIS method has the defect that the nearest ideal solution to PIS is not necessarily the farthest from NIS, which makes the evaluation result inaccurate. Therefore, based on the above motivations, this paper presents an extended TOPSIS method with unknown attribute weights information under the novel idea of Pythagorean probabilistic hesitant fuzzy environment. Meanwhile, this paper proposes a weight calculation model which can effectively deal with the extreme value given by the bias expert and solve the situation of experts with large differences of opinion. Besides, using the improved relative closeness formula, the proposed method will get a more accurate evaluation result. Therefore, the innovations of this paper are mainly the following aspects: firstly, it introduces a novel concept of the Pythagorean probabilistic hesitant fuzzy set (PyPHFS). The motivation of the new concept is that in Probabilistic hesitant fuzzy set (PHFS) only positive membership degree is considered with probabilistic information, but PyPHFS is characterized by both positive hesitant membership and negative hesitant membership degrees, with the constraint that the square sum of positive and negative hesitant membership degrees is less than or equal to one. In PHFS, the DMs are limited to a particular domain and ignore the negative membership degree with its possible occurrence chances. Every negative hesitant membership degree also has some preference as compare to others. For instance, the DMs may express their opinion in DM-problems in the form of several possible values, if one DM gives values $0.3,0.4,0.6$ for positive membership degree with their corresponding preference values 0.1 and 0.9 , the other one may reject. The possibility of rejection level with hesitancy is considered under the proposed concept. The information of chances will decrease in spite of HFSs and PHFSs. The value of the chance of occurrence with positive and negative membership degrees gives more details on the level of difference of opinion of the DMs. To deal with the uncertainty in decision making problems, the novel concept of Pythagorean probabilistic hesitant fuzzy set is proposed. The originality of the paper is given as follows:

(1) The PHFS is generalized by PyPHFS.

(2) The TOPSIS method is generalized by PyPHFS with unidentified weight information.

(3) The PyPHF-TOPSIS method is proposed to solve the PyPHF-MCDM problems with unknown weight information.

(4) We extend the distance measures and aggregation operators and apply it to the MCDM problem.

(5) A case study for the most crucial fog-haze influence factor is provided to show the effectiveness and applicability of the proposed approach.

The arrangement of the paper is as follows. Section 2 gives a review of FSs, IFSs, PyFSs, HFSs and PyHFSs. Section 3 gives some discussion about the algebraic operations of PyPHFSs. In Section 4 we exhibit distance measure and weighted distance measure, together with its properties. In Section 5 , the novel technique to handle vagueness in DM problems to sort out the finest alternative according to a list of attributes is proposed. Section 6 explains the application of the proposed MCDM method. In Section 7, a conclusion and discussion of the manuscript is given.

\section{Preliminaries}

Let us remember the fundamentals of fuzzy sets, intuitionistic fuzzy sets and Pythagorean fuzzy sets in this section for a moment. Upon review, these notions will be used here.

Definition 1 ([3]). For a fixed set $\breve{E}$. A FS $\varepsilon$ in $\breve{E}$ is presented as

$$
\varepsilon=\left\{\left\langle\ell_{x}, \rho_{\varepsilon}\left(\ell_{x}\right)\right\rangle \mid \ell_{x} \in \breve{E}\right\},
$$


for each $\ell_{x} \in \breve{E}$, the positive membership grade $\rho_{\varepsilon}: \breve{E} \rightarrow \Theta$ specifies the degree to which the element $\ell_{x}$ belongs to the fuzzy set $\varepsilon$, where $\Theta=[0,1]$ be the unit interval.

Definition 2 ([4]). For a fixed set $\breve{E}$. An IFS $\varepsilon$ in $\breve{E}$ is presented as

$$
\varepsilon=\left\{\left\langle\ell_{x}, \rho_{\varepsilon}\left(\ell_{x}\right), \tilde{n}_{\varepsilon}\left(\ell_{x}\right)\right\rangle \mid \ell_{x} \in \breve{E}\right\},
$$

for each $\ell_{x} \in \breve{E}$, the positive membership grade $\rho_{\varepsilon}: \breve{E} \rightarrow \Theta$ and the negative membership grade $\tilde{n}_{\varepsilon}: \breve{E} \rightarrow \Theta$ specifies the degree of positive and negative membership of the element $\ell_{x}$ to the Intuitionistic fuzzy set $\varepsilon$, respectively, where $\Theta=[0,1]$ is the unit interval. Moreover, it is required that $0 \leq \rho_{\varepsilon}\left(\ell_{x}\right)+\tilde{n}_{\varepsilon}\left(\ell_{x}\right) \leq 1$, for each $\ell_{x} \in \breve{E}$.

Definition 3 ([5]). For a fixed set $\breve{E}$. A PyFS $\varepsilon$ in $\breve{E}$ is presented as

$$
\varepsilon=\left\{\left\langle\ell_{x}, \rho_{\varepsilon}\left(\ell_{x}\right), \tilde{n}_{\varepsilon}\left(\ell_{x}\right)\right\rangle \mid \ell_{x} \in \breve{E}\right\},
$$

for each $\ell_{x} \in \breve{E}$, the positive membership grade $\rho_{\varepsilon}: \breve{E} \rightarrow \Theta$ and the negative membership grade $\tilde{n}_{\varepsilon}: \breve{E} \rightarrow \Theta$ specifies the degree of positive and negative membership of the element $\ell_{x}$ to the Pythagorean fuzzy set $\varepsilon$, respectively, where $\Theta=[0,1]$ is the unit interval. Furthermore, it is required that $0 \leq \rho_{\varepsilon}^{2}\left(\ell_{x}\right)+\tilde{n}_{\varepsilon}^{2}\left(\ell_{x}\right) \leq 1$, for each $\ell_{x} \in \breve{E}$.

Conventionally, $\chi_{\varkappa}=\sqrt{1-\rho_{\varepsilon}^{2}\left(\ell_{x}\right)-\tilde{n}_{\varepsilon}^{2}\left(\ell_{x}\right)}$ is said to be degree of hesitancy of $\ell_{x}$ to $\varepsilon$. In what follows, we symbolize by PyF $\hat{S}(\breve{E})$ the collection of all Pythagorean fuzzy sets in $\breve{E}$. For ease, we shall symbolize the Pythagorean fuzzy number (PyFN) by the pair $\varepsilon=\left(\rho_{\varepsilon}, \tilde{n}_{\varepsilon}\right)$.

Definition 4 ([5]). Let $\varepsilon_{1}, \varepsilon_{2} \in P y F \hat{S}(\breve{E})$. Then

(1) $\varepsilon_{1} \sqsubseteq \varepsilon_{2}$ if and only if $\rho_{\varepsilon_{1}}\left(\ell_{x}\right) \leq \rho_{\varepsilon_{2}}\left(\ell_{x}\right)$ and $\tilde{n}_{\varepsilon_{1}}\left(\ell_{x}\right) \geq \tilde{n}_{\varepsilon_{2}}\left(\ell_{x}\right)$ for each $\ell_{x} \in \breve{E}$. Clearly $\varepsilon_{1}=\varepsilon_{2}$ if $\varepsilon_{1} \sqsubseteq \varepsilon_{2}$ and $\varepsilon_{2} \sqsubseteq \varepsilon_{1}$.

(2) $\varepsilon_{1} \sqcap \varepsilon_{2}=\left\{\min \left(\rho_{\varepsilon_{1}}\left(\ell_{x}\right), \rho_{\varepsilon_{2}}\left(\ell_{x}\right)\right), \max \left(\tilde{n}_{\varepsilon_{1}}\left(\ell_{x}\right), \tilde{n}_{\varepsilon_{2}}\left(\ell_{x}\right)\right) \mid \ell_{x} \in \breve{E}\right\}$,

(3) $\varepsilon_{1} \sqcup \varepsilon_{2}=\left\{\max \left(\rho_{\varepsilon_{1}}\left(\ell_{x}\right), \rho_{\varepsilon_{2}}\left(\ell_{x}\right)\right), \min \left(\tilde{n}_{\varepsilon_{1}}\left(\ell_{x}\right), \tilde{n}_{\varepsilon_{2}}\left(\ell_{x}\right)\right) \mid \ell_{x} \in \breve{E}\right\}$,

(4) $\varepsilon_{1}^{c}=\left\{\tilde{n}_{\varepsilon_{1}}\left(\ell_{x}\right), \rho_{\varepsilon_{1}}\left(\ell_{x}\right) \mid \ell_{x} \in \breve{E}\right\}$.

Definition 5 ([9]). For a fixed set $\breve{E}$. A Hesitant Fuzzy Set (HFS) $\varepsilon$ in $\breve{E}$ is presented as

$$
\varepsilon=\left\{\left\langle\ell_{x}, h_{\varkappa}\left(\ell_{x}\right)\right\rangle \mid \ell_{x} \in \breve{E}\right\}
$$

where $h_{\varkappa}\left(\ell_{x}\right)$ is in the form of set which contained some possible values in unit interval, i.e., $[0,1]$ which represent the membership degree of $\ell_{x} \in \breve{E}$ in $\varepsilon$.

Definition 6 ([9]). Let $\varepsilon_{1}, \varepsilon_{2} \in H F S(\breve{E})$. Then

(1) $\varepsilon_{1}^{c}=\bigsqcup_{\alpha \in h_{\varepsilon_{1}}\left(\ell_{x}\right)}\{1-\alpha\}$;

(2) $\varepsilon_{1} \sqcup \varepsilon_{2}=h_{\varepsilon_{1}}\left(\ell_{x}\right) \underline{\vee} h_{\varepsilon_{2}}\left(\ell_{x}\right)=\bigsqcup_{\alpha_{1} \in h_{\varepsilon_{1}}\left(\ell_{x}\right), \alpha_{2} \in h_{\varepsilon_{2}}\left(\ell_{x}\right)} \max \left\{\alpha_{1}, \alpha_{2}\right\}$;

(3) $\varepsilon_{1} \sqcap \varepsilon_{2}=h_{\varepsilon_{1}}\left(\ell_{x}\right) \bar{\wedge} h_{\varepsilon_{2}}\left(\ell_{x}\right)=\bigsqcup_{\alpha_{1} \in h_{\varepsilon_{1}}\left(\ell_{x}\right), \alpha_{2} \in h_{\varepsilon_{2}}\left(\ell_{x}\right)} \min \left\{\alpha_{1}, \alpha_{2}\right\}$;

Definition 7 ([10]). For a fixed set $\breve{E}$. A PyHFS $\varepsilon$ in $\breve{E}$ is presented as

$$
\varepsilon=\left\{\left\langle\ell_{x}, \rho_{h_{\varkappa}}\left(\ell_{x}\right), \tilde{n}_{h_{\varkappa}}\left(\ell_{x}\right)\right\rangle \mid \ell_{x} \in \breve{E}\right\},
$$

for each $\ell_{x} \in \breve{E}$, the positive membership grade $\rho_{\varepsilon}$ and the negative membership grade $\tilde{n}_{\varkappa}$ are sets in some values in $[0,1]$, specifies the possible degree of positive and negative membership of the element $\ell_{x}$ to the Pythagorean hesitant fuzzy set $\varepsilon$, respectively. Furthermore, it is required that $\left(\max \left(\rho_{h_{\varkappa}}\left(\ell_{x}\right)\right)\right)^{2}+\left(\min \left(\tilde{n}_{h_{\varkappa}}\left(\ell_{x}\right)\right)\right)^{2} \leq 1$ 
and $\left(\min \left(\rho_{h_{\varkappa}}\left(\ell_{x}\right)\right)\right)^{2}+\left(\max \left(\tilde{n}_{h_{\varkappa}}\left(\ell_{x}\right)\right)\right)^{2} \leq 1$. For ease, we shall symbolize the Pythagorean Hesitant Fuzzy Number (PyHFN) by the pair $\varepsilon=\left(\rho_{h_{\varkappa}}, \tilde{n}_{h_{\varkappa}}\right)$.

Definition 8 ([11]). For a fixed set $\breve{E}$. A Probabilistic Hesitant Fuzzy Set (PHFS) $\varepsilon$ in $\breve{E}$ is presented as

$$
\varepsilon=\left\{\left\langle\ell_{x}, h_{\varkappa}\left(\ell_{x}\right) / p_{x}\right\rangle \mid \ell_{x} \in \breve{E}\right\}
$$

where $h_{\varkappa}\left(\ell_{x}\right)$ is subset of $[0,1]$ and $h_{\varkappa}\left(\ell_{x}\right) / p_{x}$ represent the membership degree of $\ell_{x} \in \breve{E}$ in $\varepsilon$. Furthermore, $p_{x}$ represent the possibilities of $h_{\varkappa}\left(\ell_{x}\right)$, with condition that $\sum_{x} p_{x}=1$.

\section{Pythagorean Probabilistic Hesitant Fuzzy Sets and Their Operational Laws}

In this segment, we develop the novel hybrid notion of Pythagorean Probabilistic Hesitant Fuzzy Sets (PyPHFSs) to deal with the uncertainty in decision support systems. We also introduce the basic operational laws for PyPHFSs.

Definition 9. For a fixed set $\breve{E}$. A PyPHFS $\varepsilon$ in $\breve{E}$ is presented as

$$
\varepsilon=\left\{\left\langle\ell_{x}, \rho_{h_{\varkappa}}\left(\ell_{x}\right) / p_{x}, \tilde{n}_{h_{\varkappa}}\left(\ell_{x}\right) / q_{x}\right\rangle \mid \ell_{x} \in \breve{E}\right\},
$$

for each $\ell_{x} \in \breve{E}, \rho_{h_{\varkappa}}\left(\ell_{x}\right)$ and $\tilde{n}_{h_{\varkappa}}\left(\ell_{x}\right)$ are sets of some values in $[0,1]$. Where $\rho_{h_{\varkappa}}\left(\ell_{x}\right) / p_{x} \mathcal{E} \tilde{n}_{h_{\varkappa}}\left(\ell_{x}\right) / q_{x}$ specifies the possible degree of positive and negative membership of the element $\ell_{x}$ to the Pythagorean probabilistic hesitant fuzzy set $\varepsilon$, respectively. $p_{x}$ and $q_{x}$ represent the possibilities of membership grades. In addition, there is $0 \leq \gamma_{i}, \eta_{j} \leq 1$ and $0 \leq p_{i}, q_{j} \leq 1$ with $\sum_{i=1}^{L} p_{i} \leq 1, \sum_{j=1}^{L} q_{j} \leq 1$ (L is a positive integer to describe the number of elements contained in PyPHFS), where $\gamma_{i} \in \rho_{h_{\varkappa}}\left(\ell_{x}\right), \eta_{j} \in \tilde{n}_{h_{\varkappa}}\left(\ell_{x}\right), p_{i} \in p_{x}, q_{j} \in q_{x}$. Furthermore, it is required that $\left(\max \left(\rho_{h_{\varkappa}}\left(\ell_{x}\right)\right)\right)^{2}+\left(\min \left(\tilde{n}_{h_{\varkappa}}\left(\ell_{x}\right)\right)\right)^{2} \leq 1$ and $\left(\min \left(\rho_{h_{\varkappa}}\left(\ell_{x}\right)\right)\right)^{2}+\left(\max \left(\tilde{n}_{h_{\varkappa}}\left(\ell_{x}\right)\right)\right)^{2} \leq 1$. For ease, we shall symbolize the Pythagorean Probabilistic Hesitant Fuzzy Number (PyPHFN) by the pair $\varepsilon=\left(\rho_{h_{\varkappa}} / p_{x}, \tilde{n}_{h_{\varkappa}} / q_{x}\right)$.

The collection of all Pythagorean probabilistic hesitant fuzzy sets in $\breve{E}$ is symbolized by $\operatorname{PyPHFS}(\breve{E})$

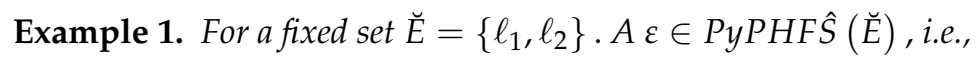

$$
\varepsilon=\left\{\begin{array}{l}
\left(\ell_{1},(0.2 / 0.3,0.5 / 0.2,0.9 / 0.5),(0.1 / 0.4,0.3 / 0.5)\right) \\
\left(\ell_{2},(0.4 / 0.6,0.7 / 0.4),(0.6 / 0 / 4,0.2 / 0.4,0.3 / 0.2)\right)
\end{array}\right\}
$$

where $0 \leq p_{x} \leq 1$ with $\sum_{x=1}^{L} p_{x} \leq 1$. Then

$$
\begin{aligned}
& \max \rho_{h_{1}}\left(\ell_{1}\right)=\max \{0.2,0.5,0.9\} \quad \max \tilde{n}_{h_{1}}\left(\ell_{1}\right)=\max \{0.1,0.3\} \\
& =0.9 \quad=0.3 \\
& \max \rho_{h_{2}}\left(\ell_{2}\right)=\max \{0.4,0.7\} \quad \max \tilde{n}_{h_{2}}\left(\ell_{2}\right)=\max \{0.6,0.2,0.3\} \\
& =0.7 \quad=0.6 \\
& \min \rho_{h_{1}}\left(\ell_{1}\right)=\min \{0.2,0.5,0.9\} \quad \min \tilde{n}_{h_{1}}\left(\ell_{1}\right)=\min \{0.1,0.3\} \\
& =0.2 \quad=0.1 \\
& \min \rho_{h_{2}}\left(\ell_{2}\right)=\min \{0.4,0.7\} \quad \min \tilde{n}_{h_{2}}\left(\ell_{2}\right)=\min \{0.6,0.2,0.3\} \\
& =0.4 \\
& =0.2
\end{aligned}
$$

it is clear that

$$
\begin{aligned}
\left(\max \left(\rho_{h_{1}}\left(\ell_{1}\right)\right)\right)^{2}+\left(\min \left(\tilde{n}_{h_{1}}\left(\ell_{1}\right)\right)\right)^{2} & =(0.9)^{2}+(0.1)^{2} \\
& =0.82 \leq 1
\end{aligned}
$$


and

$$
\begin{aligned}
\left(\min \left(\rho_{h_{1}}\left(\ell_{1}\right)\right)\right)^{2}+\left(\max \left(\tilde{n}_{h_{1}}\left(\ell_{1}\right)\right)\right)^{2} & =(0.2)^{2}+(0.3)^{2} \\
& =0.13 \leq 1
\end{aligned}
$$

So, $\left(\rho_{h_{1}}\left(\ell_{1}\right) / p, \tilde{n}_{h_{1}}\left(\ell_{1}\right) / q\right)$ is a PyPHFN. Similarly, $\left(\rho_{h_{2}}\left(\ell_{2}\right) / p, \tilde{n}_{h_{2}}\left(\ell_{2}\right) / q\right)$ is a PyPHFN. Thus, $\varepsilon \in$

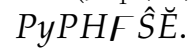

Definition 10. Let $\varepsilon_{1}=\left(\rho_{h_{x_{1}}} / p_{x_{1}}, \tilde{n}_{h_{x_{1}}} / q_{x_{1}}\right)$ and $\varepsilon_{2}=\left(\rho_{h_{x_{2}}} / p_{x_{2}}, \tilde{n}_{h_{x_{2}}} / q_{x_{2}}\right)$ be two PyPHFNs. The basic operational laws defined as

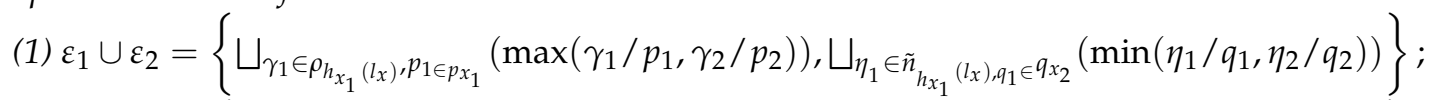

(2) $\varepsilon_{1} \cap \varepsilon_{2}=\left\{\sqcup_{\gamma_{1} \in \rho_{h_{x_{1}}\left(l_{x}\right)}, p_{1 \in p_{x_{1}}}}\left(\min \left(\gamma_{1} / p_{1}, \gamma_{2} / p_{2}\right)\right), \bigsqcup_{\eta_{1} \in \tilde{n}_{h_{x_{1}}}\left(l_{x}\right), q_{1} \in q_{x_{2}}}\left(\max \left(\eta_{1} / q_{1}, \eta_{2} / q_{2}\right)\right)\right\}$;

(3) $\varepsilon_{1}^{c}=\left\{\tilde{n}_{h_{\varkappa}} / q_{x}, \rho_{h_{\varkappa}} / p_{x}\right\}$

Definition 11. Let $\varepsilon_{1}=\left(\rho_{h_{x_{1}}} / p_{x_{1}}, \tilde{n}_{h_{x_{1}}} / q_{x_{1}}\right)$ and $\varepsilon_{2}=\left(\rho_{h_{x_{2}}} / p_{x_{2}}, \tilde{n}_{h_{x_{2}}} / q_{x_{2}}\right)$ be two PyPHFNs and $\zeta>0(\in \mathbb{R})$, then their operations are presented as:

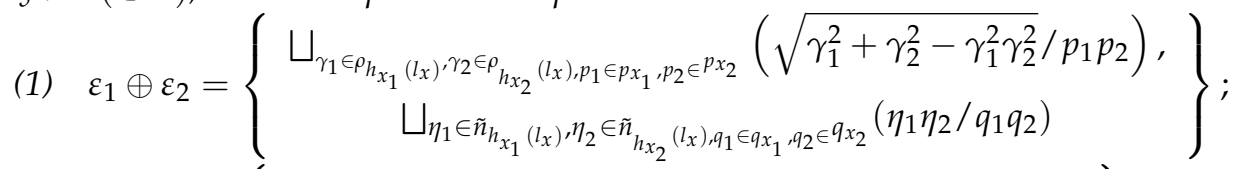

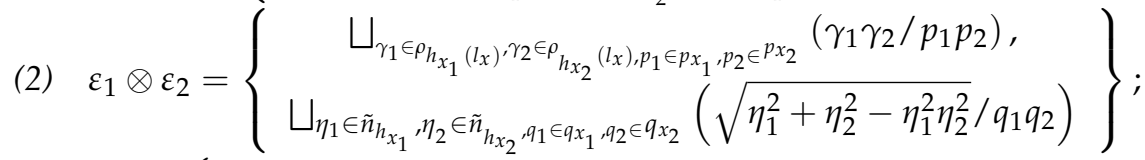

(3) $\zeta \varepsilon_{1}=\left\{\sqcup_{\gamma_{1} \in \rho_{h_{x_{1}}(l x)}, p_{1 \in p_{x_{1}}}}\left(\sqrt{1-\left(1-\gamma_{1}^{2}\right) \zeta} / p_{1}\right), \bigsqcup_{\eta_{1} \in \tilde{n}_{h_{x_{1}}}\left(l_{x}\right), q_{1} \in q_{x_{2}}}\left(\eta_{1}^{\zeta} / q_{1}\right)\right\}$;

(4) $\varepsilon_{1}^{\zeta}=\left\{\sqcup_{\gamma_{1} \in \rho_{h_{x_{1}}(l x)}, p_{1 \in p_{x_{1}}}}\left(\gamma_{1}^{\zeta} / p_{1}\right), \bigsqcup_{\eta_{1} \in \tilde{n}_{h_{x_{1}}}\left(l_{x}\right), q_{1} \in q_{x_{2}}}\left(\sqrt{1-\left(1-\eta_{1}^{2}\right)^{\zeta}} / q_{1}\right)\right\}$.

Definition 12. For any PyPHFN $\varepsilon=\left(\rho_{h_{\varkappa}} / p_{x}, \tilde{n}_{h_{\varkappa}} / q_{x}\right)$, a score function is defined as

$$
s(\varepsilon)=\left(\frac{1}{M_{\varepsilon}} \sum_{\gamma_{i} \in \rho_{h_{x}, p_{i} \in p_{h_{x}}}}\left(\gamma_{i} \cdot p_{i}\right)\right)^{2}-\left(\frac{1}{N_{\varepsilon}} \sum_{\eta_{i} \in \tilde{n}_{h_{\varkappa}, q_{i} \in q_{h_{x}}}}\left(\eta_{i} \cdot q_{i}\right)\right)^{2}
$$

where $M_{\varepsilon}$ denotes the number of elements in $\rho_{h_{\varkappa}}$ and $N_{\varepsilon}$ denotes the number of elements in $\tilde{n}_{h_{\varkappa}}$.

Definition 13. For any PyPHFN $\varepsilon=\left(\rho_{h_{\varkappa}} / p_{x}, \tilde{n}_{h_{\varkappa}} / q_{x}\right)$, an accuracy function is defined as

$$
h(\varepsilon)=\left(\frac{1}{M_{\varepsilon}} \sum_{\gamma_{i} \in \rho_{h_{x}, p_{i} \in p_{h_{x}}}}\left(\gamma_{i} \cdot p_{i}\right)\right)^{2}+\left(\frac{1}{N_{\varepsilon}} \sum_{\eta_{i} \in \tilde{n}_{h_{\varkappa}, q_{i} \in q_{h_{x}}}}\left(\eta_{i} \cdot q_{i}\right)\right)^{2}
$$

where $M_{\mathcal{\varepsilon}}$ denotes the number of elements in $\rho_{h_{\varkappa}}$ and $N_{\varepsilon}$ denotes the number of elements in $\tilde{n}_{h_{\varkappa}}$.

Definition 14. Let $\varepsilon_{1}=\left(\rho_{h_{x_{1}}} / p_{x_{1}}, \tilde{n}_{h_{x_{1}}} / q_{x_{1}}\right)$ and $\varepsilon_{2}=\left(\rho_{h_{x_{2}}} / p_{x_{2}}, \tilde{n}_{h_{x_{2}}} / q_{x_{2}}\right)$ be two PyPHFNs. Then by using the above definitions, comparison of PyPHFNs can be described as

(1) If $s\left(\varepsilon_{1}\right)>s\left(\varepsilon_{2}\right)$, then $\varepsilon_{1}>\varepsilon_{2}$.

(2) If $s\left(\varepsilon_{1}\right)=s\left(\varepsilon_{2}\right)$, and $h\left(\varepsilon_{1}\right)>h\left(\varepsilon_{2}\right)$ then $\varepsilon_{1}>\varepsilon_{2}$ 


\section{Methodological Development of Pythagorean Probabilistic Hesitant Fuzzy Entropy Measure}

In this segment, the proposed extended distance measures and the weighted extended distance measures for PyPHFSs are defined. Then, a proposed entropy measure for PyPHFS is presented for quantitative evaluation of randomness of a PyPHFS.

\subsection{Distance Measure for Pyphfss}

Definition 15. For any two PyPHFSs $\varepsilon=\left\{\rho_{\varepsilon_{i}} / p_{\varepsilon_{i}}, \tilde{n}_{\varepsilon_{j}} / q_{\varepsilon_{j}}\right\}$ and $\vartheta=\left\{\rho_{\vartheta_{i}} / p_{\vartheta_{i}}, \tilde{n}_{\vartheta_{j}} / q_{\vartheta_{j}}\right\}$, where $i=$ $1,2, \ldots, M_{\varepsilon} ; j=1,2, \ldots, N_{\varepsilon} ; \tilde{\imath}=1,2, \ldots, M_{\vartheta}$ and $\hat{\jmath}=1,2, \ldots, N_{\vartheta}$. For a real number $\zeta>0$, we defined distance measure between $\varepsilon$ and $\vartheta$ as:

$$
d^{\circ}(\varepsilon, \vartheta)=\left(\sum_{x=1}^{n} \frac{1}{2 n}\left(\begin{array}{c}
\left|\frac{1}{M_{\varepsilon}} \sum_{i=1}^{M_{\varepsilon}}\left(\gamma_{\varepsilon_{i}} p_{\varepsilon_{i}}\right)^{2}-\frac{1}{M_{\vartheta}} \sum_{\tilde{\imath}=1}^{M_{\vartheta}}\left(\gamma_{\vartheta_{i}} p_{\vartheta_{\tilde{i}}}\right)^{2}\right|^{\zeta}+ \\
\left|\frac{1}{N_{\varepsilon}} \sum_{j=1}^{N_{\varepsilon}}\left(\eta_{\varepsilon_{j}} q_{\varepsilon_{j}}\right)^{2}-\frac{1}{N_{\vartheta}} \sum_{\hat{\jmath}=1}^{N_{\vartheta}}\left(\eta_{\vartheta_{j}} q_{\vartheta_{\hat{\jmath}}}\right)^{2}\right|^{\zeta}
\end{array}\right)\right)^{\frac{1}{\zeta}},
$$

where $\gamma_{\varepsilon_{i}} \in \rho_{\varepsilon_{i}}, \gamma_{\vartheta_{i}} \in \rho_{\vartheta_{\tilde{i}}}, \eta_{\varepsilon_{j}} \in \tilde{n}_{\varepsilon_{j}}, \eta_{\vartheta_{\hat{\jmath}}} \in \tilde{n}_{\vartheta_{\hat{\jmath}}}$.

Definition 16. For any two PyPHFSs $\varepsilon=\left\{\rho_{\varepsilon_{i}} / p_{\varepsilon_{i}}, \tilde{n}_{\varepsilon_{j}} / q_{\varepsilon_{j}}\right\}$ and $\vartheta=\left\{\rho_{\vartheta_{i}} / p_{\vartheta_{i}}, \tilde{n}_{\vartheta_{\hat{\jmath}}} / q_{\vartheta_{\hat{\jmath}}}\right\}$, where $i=$ $1,2, \ldots, M_{\varepsilon} ; j=1,2, \ldots, N_{\varepsilon} ; \tau=1,2, \ldots, M_{\vartheta}$ and $\hat{\jmath}=1,2, \ldots, N_{\vartheta}$. For a real number $\zeta>0$, we defined weighted distance measure between $\varepsilon$ and $\vartheta$ as:

$$
d^{\circ}(\varepsilon, \vartheta)=\left(\sum_{x=1}^{n} \frac{1}{2 n} \omega_{x}\left(\begin{array}{c}
\left|\frac{1}{M_{\varepsilon}} \sum_{i=1}^{M_{\varepsilon}}\left(\gamma_{\varepsilon_{i}} p_{\varepsilon_{i}}\right)^{2}-\frac{1}{M_{\vartheta}} \sum_{\tilde{\imath}=1}^{M_{\vartheta}}\left(\gamma_{\vartheta_{i}} p_{\vartheta_{\tau}}\right)^{2}\right|^{\zeta}+ \\
\left|\frac{1}{N_{\varepsilon}} \sum_{j=1}^{N_{\varepsilon}}\left(\eta_{\varepsilon_{j}} q_{\varepsilon_{j}}\right)^{2}-\frac{1}{N_{\vartheta}} \sum_{\hat{\jmath}=1}^{N_{\vartheta}}\left(\eta_{\vartheta_{\hat{\jmath}}} q_{\vartheta_{\hat{\jmath}}}\right)^{2}\right|^{\zeta}
\end{array}\right)\right)^{\frac{1}{\zeta}},
$$

where $\omega_{x}=\left(\omega_{1}, \ldots . ., \omega_{n}\right)^{T}$ is the weight vector and $\gamma_{\varepsilon_{i}} \in \rho_{\varepsilon_{i}}, \gamma_{\vartheta_{i}} \in \rho_{\vartheta_{\hat{i}}}, \eta_{\varepsilon_{j}} \in \tilde{n}_{\varepsilon_{j}}, \eta_{\vartheta_{j}} \in \tilde{n}_{\vartheta_{j}}$.

Theorem 1. Let $\varepsilon$ and $\vartheta$ be two PyPHFSs, then the distance measure has the following constraints:

(P1) $0 \leq d^{\circ}(\varepsilon, \vartheta) \leq 1$

(P2) $d^{\circ}(\varepsilon, \vartheta)=d^{\circ}(\vartheta, \varepsilon)$;

(P3) $d^{\circ}(\varepsilon, \vartheta)=0 \Longleftrightarrow \varepsilon=\vartheta$;

Proof. Straight forward

\subsection{Entropy Measure for Pyphfss}

The weight information of attributes/criteria is very important in decision making problems. Many scholars focus on decision making problems with incomplete or unknown attributes weight information in different fuzzy environments [62,63]. Entropy [48] is a conventional term from information theory which is also used to determine weight of attributes. The larger the value of entropy in a given attribute is, the smaller the differences in the ratings of alternatives with respect to this attribute. In turn, this means that this kind of attribute supplies less information and has a smaller weight.

Definition 17. The information of Shannon entropy $E\left(E_{1}, E_{2}, E_{3}, \ldots, E_{m}\right)$ for PyPHFS is defined as

$$
\frac{-1}{\ln (m)} \sum_{i=1}^{m}\left(\rho_{h_{\varkappa}}\left(\ln \rho_{h_{\varkappa}}\right) \times p_{x}+\tilde{n}_{h_{\varkappa}}\left(\ln \tilde{n}_{h_{\varkappa}}\right) \times q_{x}\right)
$$

Properties of Entropy Measure

For any two PyPHFSs $\varepsilon$ and $\vartheta$, the entropy measure $E(\varepsilon)$ and $E(\vartheta)$ fulfill the given axioms: 
(a) $\quad E(\varepsilon)=0 \Longleftrightarrow \varepsilon$ is a crisp set.

(b) $\quad E(\varepsilon)=1 \Longleftrightarrow \gamma_{\varepsilon_{j}}\left(\ell_{x}\right)=\eta_{\varepsilon_{j}}\left(\ell_{x}\right) \forall \ell_{x} \in \breve{E}$

(c) $E(\varepsilon) \leq E(\vartheta)$ if $\varepsilon \preceq_{\text {PyPHFS } \vartheta}$

(d) $E(\varepsilon)=E\left(\varepsilon^{c}\right)$

\section{Pythagorean Probabilistic Hesitant Fuzzy Mcdm Topsis Technique}

Let $\bar{A}=\left\{\bar{A}_{1}, \bar{A}_{2}, \ldots ., \bar{A}_{k}\right\}$ be a set of alternatives, $\hat{C}=\left\{\hat{C}_{1}, \hat{C}_{2}, \ldots ., \hat{C}_{n}\right\}$ be a set of criteria and $r$ be the number of DMs, $\mathrm{DM}_{e}(e=1,2, \ldots, r)$, to show their perception about $\mathrm{k}$ alternatives with respect to the $n$ criteria by taking $\varepsilon_{i j}^{(e)}=\left(\rho_{i j}^{(e)}, \tilde{n}_{i j}^{(e)}\right)$. The decision matrix of the eth decision maker is presented as:

$$
\varepsilon^{(e)}=\left[\varepsilon_{i j}^{(e)}\right]_{k \times n}=\left[\left(\rho_{\varepsilon_{i j}}^{(e)} / p_{\varepsilon_{i j}}, \tilde{n}_{\varepsilon_{i j}}^{(e)} / q_{\varepsilon_{i j}}\right)\right]_{k \times n}
$$

where

$$
\varepsilon^{(e)}=\begin{gathered}
\hat{C}_{1} \\
\bar{A}_{1} \\
\bar{A}_{2} \\
\ldots \\
\ldots \\
\bar{A}_{k}
\end{gathered}\left[\begin{array}{ccccc}
\left(\rho_{\varepsilon_{1}}^{(e)} / p_{\varepsilon_{11}}, \tilde{n}_{\varepsilon_{11}}^{(e)} / q_{\varepsilon_{11}}\right) & \left(\rho_{\varepsilon_{12}}^{(e)} / p_{\varepsilon_{12}}, \tilde{n}_{\varepsilon_{2}}^{(e)} / q_{\varepsilon_{12}}\right) & \ldots & \left(\rho_{\varepsilon_{1 n}}^{(e)} / p_{\varepsilon_{1 n}}, \tilde{n}_{\varepsilon_{1 n}}^{(e)} / q_{\varepsilon_{1 n}}\right) \\
\left(\rho_{\varepsilon_{21}}^{(e)} / p_{\varepsilon_{21}}, \tilde{n}_{\varepsilon_{21}}^{(e)} / q_{\varepsilon_{21}}\right) & \left(\rho_{\varepsilon_{22}}^{(e)} / p_{\varepsilon_{22}}, \tilde{n}_{\varepsilon_{22}}^{(e)} / q_{\varepsilon_{22}}\right) & \ldots & \left(\rho_{\varepsilon_{2 n}}^{(e)} / p_{\varepsilon_{2 n}}, \tilde{n}_{\varepsilon_{2 n}}^{(e)} / q_{\varepsilon_{2 n}}\right) \\
\ldots & \ldots & \ldots & \ldots \\
\left(\rho_{\varepsilon_{k 1}}^{(e)} / p_{\varepsilon_{k 1}}, \tilde{n}_{\varepsilon_{k 1}}^{(e)} / q_{\varepsilon_{k 1}}\right) & \left(\rho_{\varepsilon_{k 2}}^{(e)} / p_{\varepsilon_{k 2}}, \tilde{n}_{\varepsilon_{k 2}}^{(e)} / q_{\varepsilon_{k 2}}\right) & \ldots & \left(\rho_{\varepsilon_{k n}}^{(e)} / p_{\varepsilon_{k n}}, \tilde{n}_{\varepsilon_{k n}}^{(e)} / q_{\varepsilon_{k n}}\right)
\end{array}\right]
$$

\section{Pyphf-Topsis Method}

This method has two main parts. Firstly, a method based on TOPSIS for calculating the weights of criteria/attributes utilizing the proposed entropy measure for PyPHFNs is presented. In the last part, we consider a ranking procedure based on degree of similarity to ideal solution. Steps for solving the PyPHF MCDM problem are presented as follows:

Step 1. Firstly, we collect the information in the form of PyPHFNs given by the decision makers (DMs). Step 2. In this step, we normalized the data specified by DMs, since the decision matrix may have some benefit and cost criteria altogether, as follows:

$$
\begin{aligned}
g_{i j}^{(e)} & =\left\{\begin{array}{cc}
\varepsilon_{i j}^{(e)} & \text { for benefit criteria } C_{j,}, \\
\left(\varepsilon_{i j}^{(e)}\right)^{c} & \text { for cost criteria } C_{j},
\end{array}\right. \\
e & =1,2, \ldots ., r, \quad i=1,2, \ldots, k, j=1,2, \ldots, n,
\end{aligned}
$$

where $\left(\varepsilon_{i j}^{(e)}\right)^{c}$ is complement of $\varepsilon_{i j}^{(e)}$, that is, $\left(\varepsilon_{i j}^{(e)}\right)^{c}=\left(\tilde{n}_{\varepsilon_{i j}}^{(e)}, \rho_{\varepsilon_{i j}}^{(e)}\right)$.

Step 3. The weights of the criteria are calculated through proposed entropy measure in the following way. The entropy measure corresponding to each criterion is:

$$
\begin{aligned}
E\left(\varepsilon_{j}\right) & =E\left(\varepsilon_{1 j}, \varepsilon_{2 j}, \ldots ., \varepsilon_{k j}\right), j=1,2, \ldots, n \\
& =\frac{-1}{\ln (m)} \sum_{i=1}^{m}\left(\rho_{h_{\varkappa}}\left(\ln \rho_{h_{\varkappa}}\right) \times p_{x}+\tilde{n}_{h_{\varkappa}}\left(\ln \tilde{n}_{h_{\varkappa}}\right) \times q_{x}\right)
\end{aligned}
$$

Then,

$$
W\left(\varepsilon_{j}\right)=\frac{1-E\left(\varepsilon_{j}\right)}{\sum_{j=1}^{n}\left(1-E\left(\varepsilon_{j}\right)\right)}
$$

Thus weights of criteria are found as $W\left(\varepsilon_{j}\right)=\left[W\left(\varepsilon_{1}\right), \ldots, W\left(\varepsilon_{n}\right)\right]^{T}$.

Step 4. In this step, the TOPSIS method is applied on the calculated criteria weights to rank the alternatives corresponding to each decision matrix in the following way: 
Step 4a. Determine weighted $\mathrm{NĐM}^{e}$ through the evaluated criteria's weights in the following way:

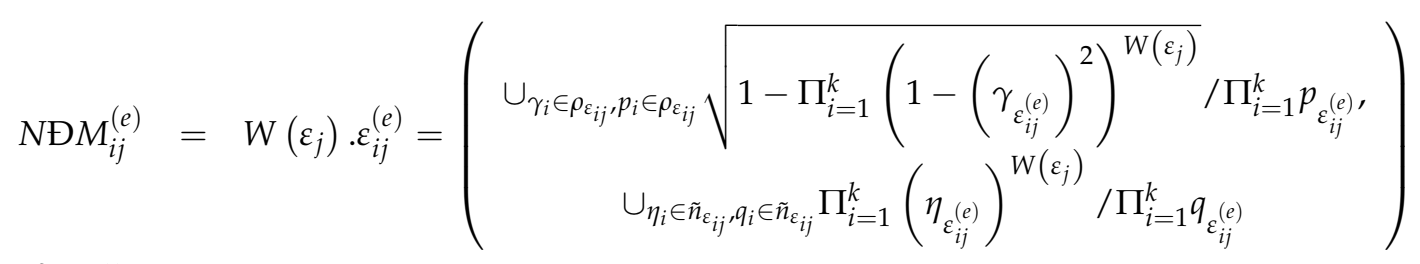

for all $e=1,2, \ldots, r$.

Step $4 \mathrm{~b}$. Derive PIS $(e)$ and $\mathrm{NIS}^{(e)}$ for all weighted $\mathrm{NĐM}^{(e)}$, for all $\mathrm{DM}_{e}(e=1,2, \ldots, r)$ as follows [30]:

$$
\begin{aligned}
P I S^{(e)} & =\left\{P I S_{j}^{(e)}\right\}_{r \times n}=\left\{\left(N Đ M_{i j}^{(e)}\right): \max _{i}\left[s\left(N Đ M_{i j}^{(e)}\right)\right]\right\} \\
\text { for } j & =1,2, \ldots, n \\
N I S^{(e)} & =\left\{N I S_{j}^{(e)}\right\}_{r \times n}=\left\{\left(N Đ M_{i j}^{(e)}\right): \min _{i}\left[s\left(N Đ M_{i j}^{(e)}\right)\right]\right\} \\
\text { for } j & =1,2, \ldots, n
\end{aligned}
$$

Step 4c. Consider the evaluated criteria weights. Using weighted distance measure of weighted $\mathrm{NĐM}^{(e)}$ from PIS ${ }^{(e)}$ and $\mathrm{NIS}^{(e)}$ are denoted by $\mathrm{EIS}_{i}^{+}$and $\mathrm{EIS}_{i}^{-}$, respectively, and are calculated corresponding to each $\mathrm{DM}_{e}$ in the following way:

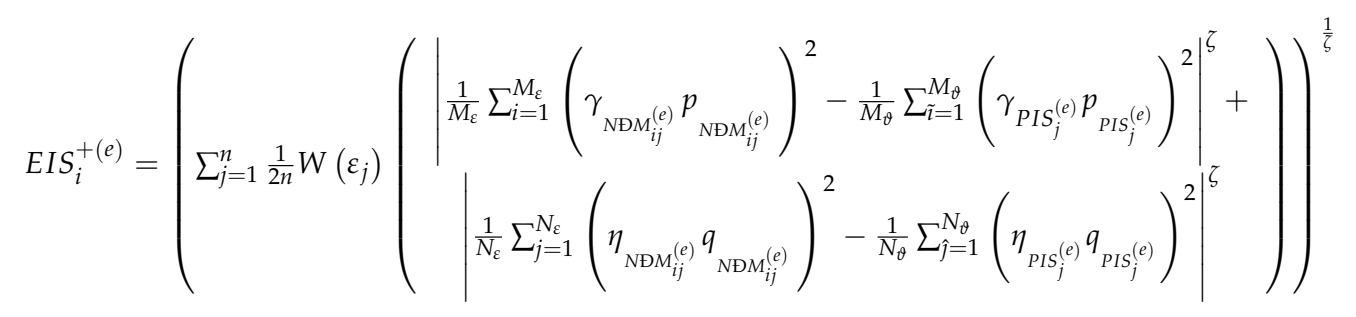

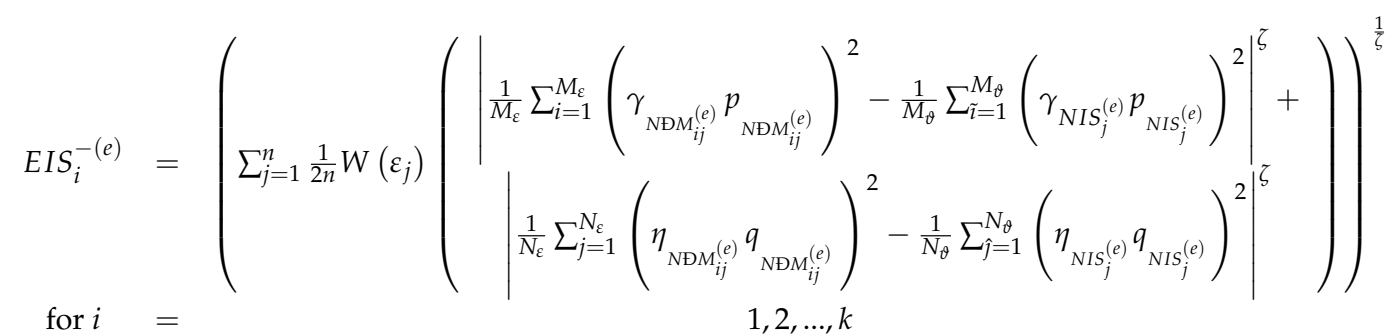

Step $4 \mathrm{~d}$. The revised closeness indices for all $\mathrm{DM}_{e}$ of the alternatives are determined in the following way:

$$
\hat{R} C I_{i}^{e}=\frac{E I S_{i}^{-(e)}}{E I S_{i}^{-(e)}+E I S_{i}^{+(e)}}
$$

Sep 5. Rank the alternative and choose the most desirable alternative having minimum distance.

The flowchart of the proposed technique is given in Figure 1: 


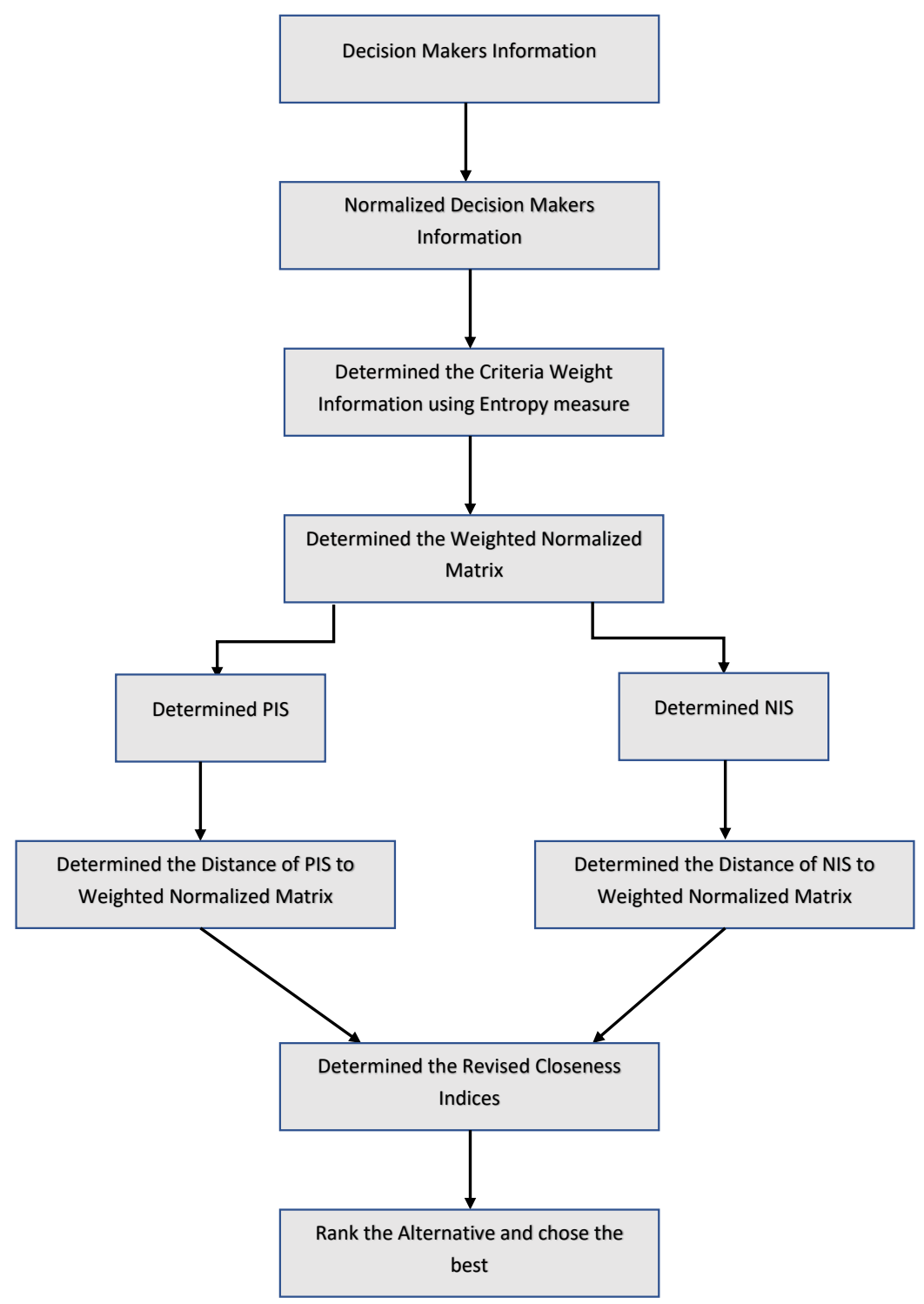

Figure 1. Flowchart of the proposed TOPSIS technique.

\section{Numerical Example}

In this section, we apply the developed decision making method to the fog-haze factor assessment problem to demonstrate the reliability and effectiveness of the proposed approach.

\section{Case Study}

The rapid development of the economy and the acceleration of urbanization cause environmental problems, especially air pollution, which is increasingly prominent in Pakistan. Frequent fog-haze weather has affected people's production and life, which attracts the Pakistani government's great attention. Prime Minister Imran Khan called for more efforts to effectively deal with heavy pollution weather and strengthen research on the formation mechanism of fog-haze at Pakistan's Two Sessions in 2019. Relevant departments of all provinces attach great importance to the prediction, early warning, prevention and control of fog-haze. The influence factors of fog-haze weather are complex and finding the most critical influence factor is important, which requires many experts to participate in the analysis of fog-haze factor. 
Lahore, as the capital city of Punjab province of Pakistan, is increasingly polluted by fog-haze weather accompanied by the development of the economy in recent years, which is not conducive to Lahore's economic development. In general, the main influence factors of fog-haze weather are PM10 concentration $\bar{A}_{1}$, PM2.5 concentration $\bar{A}_{2}$, geographical conditions $\bar{A}_{3}$, meteorological condition $\bar{A}_{4}$ and PM1.7 concentration $\bar{A}_{3}$. To assess the most critical influence factor of fog-haze weather under the list of criteria are $\hat{C}_{1}, \hat{C}_{2} \hat{C}_{3}$ and $\hat{C}_{4}$, the city's environmental protection department invites a group of related experts in the industry to evaluate the four influence factors. Because there exists too much uncertainty, the preference information given by the DMs is presented in the form of Pythagorean Probabilistic hesitant fuzzy information. To solve the MCDM problem by the developed methodology, the following calculations are achieved:

Step 1. The decision maker information in the form of PyPHFNs is given in Table 1;

Table 1. Collective information of decision makers.

\begin{tabular}{ccccc}
\hline $\mathcal{E}^{(e)}$ & $\hat{C}_{1}$ & $\hat{C}_{\mathbf{2}}$ & $\hat{C}_{3}$ & $\hat{C}_{4}$ \\
\hline \multirow{2}{*}{$\bar{A}_{1}$} & $(0.4 / 0.6,0.6 / 0.4)$ & $(0.1 / 1)$ & $(0.1 / 0.9,0.3 / 0.1)$ & $(0.6 / 0.4,0.5 / 0.6)$ \\
& $(0.2 / 0.6,0.3 / 0.4)$ & $(0.6 / 0.6,0.8 / 0.4)$ & $(0.6 / 0.7,0.7 / 0.3)$ & $(0.1 / 1)$ \\
\hline \multirow{2}{*}{$\bar{A}_{2}$} & $(0.1 / 0.3,0.3 / 0.7)$ & $(0.5 / 0.4,0.6 / 0.6)$ & $(0.4 / 1)$ & $(0.3 / 0.2,0.2 / 0.8)$ \\
& $(0.5 / 1)$ & $(0.3 / 0.7,0.4 / 0.3)$ & $(0.3 / 0.6,0.2 / 0.4)$ & $(0.6 / 0.5,0.3 / 0.5)$ \\
\hline \multirow{2}{*}{$\bar{A}_{3}$} & $(0.5 / 0.5,0.7 / 0.5)$ & $(0.1 / 1)$ & $(0.5 / 0.5,0.6 / 0.5)$ & $(0.1 / 0.1,0.1 / 0.9)$ \\
& $(0.1 / 0.5,0.2 / 0.5)$ & $(0.3 / 0.4,0.4 / 0.6)$ & $(0.3 / 0.9,0.1 / 0.1)$ & $(0.7 / 1)$ \\
\hline \multirow{2}{*}{$\bar{A}_{4}$} & $(0.4 / 0.4,0.6 / 0.6)$ & $(0.7 / 0.5,0.9 / 0.5)$ & $(0.2 / 1)$ & $(0.4 / 0.5,0.6 / 0.5)$ \\
& $(0.3 / 1)$ & $(0.1 / 0.5,0.1 / 0.5)$ & $(0.3 / 0.2,0.6 / 0.8)$ & $(0.3 / 0.9,0.2 / 0.1)$ \\
\hline \multirow{2}{*}{$\bar{A}_{5}$} & $(0.3 / 0.3,0.6 / 0.7)$ & $(0.3 / 1)$ & $(0.7 / 0.4,0.6 / 0.6)$ & $(0.7 / 0.3,0.4 / 0.7)$ \\
& $(0.2 / 0.6,0.3 / 0.4)$ & $(0.6 / 0.8,0.3 / 0.2)$ & $(0.1 / 0.1,0.3 / 0.9)$ & $(0.2 / 1)$ \\
\hline
\end{tabular}

Step 2. Information given by DMs are benefit criteria, so normalized values are carried out in Table 2, as follows

Table 2. Normalized collective information of decision makers.

\begin{tabular}{ccccc}
\hline $\mathcal{\varepsilon}^{(e)}$ & $\hat{\boldsymbol{C}}_{\mathbf{1}}$ & $\hat{\boldsymbol{C}}_{\mathbf{2}}$ & $\hat{\boldsymbol{C}}_{\mathbf{3}}$ & $\hat{\boldsymbol{C}}_{\mathbf{4}}$ \\
\hline \multirow{2}{*}{$\bar{A}_{1}$} & $(0.4 / 0.6,0.6 / 0.4)$ & $(0.1 / 1)$ & $(0.1 / 0.9,0.3 / 0.1)$ & $(0.6 / 0.4,0.5 / 0.6)$ \\
& $(0.2 / 0.6,0.3 / 0.4)$ & $(0.6 / 0.6,0.8 / 0.4)$ & $(0.6 / 0.7,0.7 / 0.3)$ & $(0.1 / 1)$ \\
\hline \multirow{2}{*}{$\bar{A}_{2}$} & $(0.1 / 0.3,0.3 / 0.7)$ & $(0.5 / 0.4,0.6 / 0.6)$ & $(0.4 / 1)$ & $(0.3 / 0.2,0.2 / 0.8)$ \\
& $(0.5 / 1)$ & $(0.3 / 0.7,0.4 / 0.3)$ & $(0.3 / 0.6,0.2 / 0.4)$ & $(0.6 / 0.5,0.3 / 0.5)$ \\
\hline \multirow{2}{*}{$\bar{A}_{3}$} & $(0.5 / 0.5,0.7 / 0.5)$ & $(0.1 / 1)$ & $(0.5 / 0.5,0.6 / 0.5)$ & $(0.1 / 0.1,0.1 / 0.9)$ \\
& $(0.1 / 0.5,0.2 / 0.5)$ & $(0.3 / 0.4,0.4 / 0.6)$ & $(0.3 / 0.9,0.1 / 0.1)$ & $(0.7 / 1)$ \\
\hline \multirow{2}{*}{$\bar{A}_{4}$} & $(0.4 / 0.4,0.6 / 0.6)$ & $(0.7 / 0.5,0.9 / 0.5)$ & $(0.2 / 1)$ & $(0.4 / 0.5,0.6 / 0.5)$ \\
& $(0.3 / 1)$ & $(0.1 / 0.5,0.1 / 0.5)$ & $(0.3 / 0.2,0.6 / 0.8)$ & $(0.3 / 0.9,0.2 / 0.1)$ \\
\hline \multirow{2}{*}{$\bar{A}_{5}$} & $(0.3 / 0.3,0.6 / 0.7)$ & $(0.3 / 1)$ & $(0.7 / 0.4,0.6 / 0.6)$ & $(0.7 / 0.3,0.4 / 0.7)$ \\
& $(0.2 / 0.6,0.3 / 0.4)$ & $(0.6 / 0.8,0.3 / 0.2)$ & $(0.1 / 0.1,0.3 / 0.9)$ & $(0.2 / 1)$ \\
\hline
\end{tabular}

Step 3. Compute the weight information for attributes/criteria using the proposed entropy measure of PyPHFNs as follows

$$
W=\left(W_{1}=0.110, W_{2}=0.387, W_{3}=0.207, W_{4}=0.296\right)
$$

Step 4a. Weighted normalized matrix is computed in Table 3, as follows. 
Table 3. (a) Weighted normalized matrix. (b) Weighted normalized matrix.

\begin{tabular}{|c|c|c|}
\hline \multicolumn{3}{|c|}{ (a) } \\
\hline$\varepsilon^{(e)}$ & $\hat{C}_{1}$ & $\hat{C}_{2}$ \\
\hline \multirow{2}{*}{$\bar{A}_{1}$} & $(0.137826 / 0.6,0.218875 / 0.4)$ & $(0.062305 / 1)$ \\
\hline & $(0.837748 / 0.6,0.875958 / 0.4)$ & $(0.820625 / 0.6,0.917267 / 0.4)$ \\
\hline \multirow{2}{*}{$\bar{A}_{2}$} & $(0.03324 / 0.3,0.10159 / 0.7)$ & $(0.324591 / 0.4,0.398273 / 0.6)$ \\
\hline & $(0.926588 / 1)$ & $(0.627547 / 0.7,0.701451 / 0.3)$ \\
\hline \multirow{2}{*}{$\bar{A}_{3}$} & $(0.176492 / 0.5,0.267192 / 0.5)$ & $(0.062305 / 1)$ \\
\hline & $(0.776247 / 0.5,0.837748 / 0.5)$ & $(0.627547 / 0.4,0.701451 / 0.6)$ \\
\hline \multirow{2}{*}{$\bar{A}_{4}$} & $(0.137826 / 0.4,0.218875 / 0.6)$ & $(0.478956 / 0.5,0.688572 / 0.5)$ \\
\hline & $(0.875958 / 1)$ & $(0.410204 / 0.5,0.410204 / 0.5)$ \\
\hline \multirow{2}{*}{$\bar{A}_{5}$} & $(0.10159 / 0.3,0.218875 / 0.7)$ & $(0.189315 / 1)$ \\
\hline & $(0.837748 / 0.6,0.875958 / 0.4)$ & $(0.820625 / 0.8,0.627547 / 0.2)$ \\
\hline \multicolumn{3}{|c|}{ (b) } \\
\hline$\varepsilon^{(e)}$ & $\hat{C}_{3}$ & $\hat{\hat{C}_{4}}$ \\
\hline \multirow{2}{*}{$\bar{A}_{1}$} & $(0.045588 / 0.9,0.139043 / 0.1)$ & $(0.351778 / 0.4,0.285708 / 0.6)$ \\
\hline & $(0.899658 / 0.7,0.928828 / 0.3)$ & $(0.505825 / 1)$ \\
\hline \multirow{2}{*}{$\bar{A}_{2}$} & $(0.188275 / 1)$ & $(0.165921 / 0.2,0.109593 / 0.8)$ \\
\hline & $(0.779407 / 0.6,0.71666 / 0.4)$ & $(0.859672 / 0.5,0.700209 / 0.5)$ \\
\hline \multirow{2}{*}{$\bar{A}_{3}$} & $(0.240441 / 0.5,0.297057 / 0.5)$ & $(0.054502 / 0.1,0.054502 / 0.9)$ \\
\hline & $(0.779407 / 0.9,0.620869 / 0.1)$ & $(0.899806 / 1)$ \\
\hline \multirow{2}{*}{$\bar{A}_{4}$} & $(0.091731 / 1)$ & $(0.224275 / 0.5,0.351778 / 0.5)$ \\
\hline & $(0.779407 / 0.2,0.899658 / 0.8)$ & $(0.700209 / 0.9,0.621019 / 0.1)$ \\
\hline \multirow{2}{*}{$\bar{A}_{5}$} & $(0.3607 / 0.4,0.297057 / 0.6)$ & $(0.425093 / 0.3,0.224275 / 0.7)$ \\
\hline & $(0.620869 / 0.1,0.72 / 0.9)$ & $(0.621019 / 1)$ \\
\hline
\end{tabular}

Step $\mathbf{4 b .}$ Positive and negative ideal solution are computed in Table 4, as follows

Table 4. (a) Positive ideal solution (PIS). (b) Negative ideal solution (NIS).

\begin{tabular}{cccc}
\hline \multicolumn{4}{c}{$(\mathbf{a})$} \\
\hline$(0.176 / 0.5,0.267 / 0.5)$ & $(0.479 / 0.5,0.689 / 0.5)$ & $(0.36 / 0.4,0.297 / 0.6)$ & $(0.352 / 0.4,0.286 / 0.6)$ \\
$(0.776 / 0.5,0.837 / 0.5)$ & $(0.41 / 0.5,0.41 / 0.5)$ & $(0.621 / 0.1,0.779 / 0.9)$ & $(0.506 / 1)$ \\
\hline \multicolumn{5}{c}{$(\mathbf{b})$} & $(0.046 / 0.9,0.139 / 0.1)$ & $(0.055 / 0.1,0.055 / 0.9)$ \\
\hline$(0.033 / 0.3,0.102 / 0.7)$ & $(0.062 / 1)$ & $(0.899 / 0.7,0.929 / 0.3)$ & $(0.899 / 1)$ \\
$(0.927 / 1)$ & $(0.821 / 0.6,0.917 / 0.4)$ & \\
\hline
\end{tabular}

Step 4c. Weighted distance measure of PIS and NIS to weighted normalized matrix are computed as

\begin{tabular}{|l|l|l|l|l|}
\hline 0.078016 & 0.045291 & 0.075142 & 0.119511 & 0.045982 \\
\hline
\end{tabular}

and

\begin{tabular}{|l|l|l|l|l|}
\hline 0.058334 & 0.067631 & 0.037303 & 0.093502 & 0.066251 \\
\hline
\end{tabular}

Step 5. Ranking of the alternative is

\begin{tabular}{|l|l|l|l|l|}
\hline 0.427824 & 0.598916 & 0.331744 & 0.438951 & 0.590297 \\
\hline
\end{tabular}

Hence $\bar{A}_{3}$ alternative has the minimum distance, so it is the best alternative in the given list of alternatives. 


\section{Comparison Analysis}

To verify the effectiveness of our proposed decision making method with intuitionistic hesitant fuzzy information, we make a comparative analysis between the proposed method and the previous method [18].

In [18] authors presented the similarity measures based on distance and cosine function; for comparison, the data set is shown in Table 5, as follows

Table 5. Collective information of decision makers.

\begin{tabular}{cccc}
\hline$\varepsilon^{(e)}$ & $\hat{C}_{1}$ & $\hat{C}_{2}$ & $\hat{C}_{3}$ \\
\hline $\bar{A}_{1}$ & $(0.8,0.6,0.5)(0.1,0.2,0.4)$ & $(0.6,0.4)(0.4,0.5)$ & $(0.9,0.6,0.5)(0.1,0.3,0.4)$ \\
\hline $\bar{A}_{2}$ & $(0.7,0.5,0.4)(0.3,0.4,0.4)$ & $(0.6,0.4,0.2)(0.3,0.3,0.5)$ & $(0.8,0.4)(0.2,0.3)$ \\
\hline $\bar{A}_{3}$ & $(0.7,0.5,0.3)(0.2,0.2,0.6)$ & $(0.9,0.7,0.5)(0.1,0.2,0.4)$ & $(0.5,0.4,0.3)(0.4,0.6,0.6)$ \\
\hline $\bar{A}_{4}$ & $(0.5,0.4,0.3)(0.3,0.5,0.6)$ & $(0.7,0.5)(0.2,0.3)$ & $(0.8,0.7)(0.1,0.3)$ \\
\hline
\end{tabular}

Given weight vector is

$$
W=\left(W_{1}=0.3, W_{2}=0.5, W_{3}=0.2\right)
$$

Firstly, we calculate the weighted normalized decision matrix in Table 6, as follows

Table 6. (a) Weighted normalized matrix. (b) Weighted normalized matrix.

\begin{tabular}{|c|c|c|}
\hline \multicolumn{3}{|c|}{ (a) } \\
\hline$\varepsilon^{(e)}$ & $\hat{C}_{1}$ & $\hat{C}_{2}$ \\
\hline $\bar{A}_{1}$ & $(0.51,0.35,0.29)(0.50,0.61,0.76)$ & $(0.45,0.29)(0.63,0.70)$ \\
\hline $\bar{A}_{2}$ & $(0.43,0.29,0.23)(0.70,0.76,0.76)$ & $(0.45,0.29,0.14)(0.55,0.55,0.70)$ \\
\hline $\bar{A}_{3}$ & $(0.43,0.29,0.17)(0.62,0.62,0.86)$ & $(0.75,0.53,0.37)(0.32,0.45,0.63)$ \\
\hline $\bar{A}_{4}$ & $(0.29,0.23,0.17)(0.70,0.81,0.86)$ & $(0.53,0.37)(0.45,0.55)$ \\
\hline \multicolumn{3}{|c|}{ (b) } \\
\hline$\varepsilon^{(e)}$ & \multicolumn{2}{|c|}{$\hat{C}_{3}$} \\
\hline $\bar{A}_{1}$ & \multicolumn{2}{|c|}{$(0.53,0.29,0.24)(0.63,0.79,0.83)$} \\
\hline $\bar{A}_{2}$ & \multicolumn{2}{|c|}{$(0.43,0.19)(0.72,0.79)$} \\
\hline $\bar{A}_{3}$ & \multicolumn{2}{|c|}{$(0.24,0.19,0.14)(0.83,0.90,0.90)$} \\
\hline $\bar{A}_{4}$ & \multicolumn{2}{|c|}{$(0.43,0.35)(0.63,0.79)$} \\
\hline
\end{tabular}

Positive and the negative ideal is computed in Table 7 as follows

Table 7. (a) PIS; (b) NIS.

\begin{tabular}{ccc}
\hline \multicolumn{3}{c}{$(\mathbf{a})$} \\
\hline$(0.51,0.35,0.29)(0.50,0.61,0.76)$ & $(0.75,0.53,0.37)(0.32,0.45,0.63)$ & $(0.43,0.35)(0.63,0.79)$ \\
\hline & $(\mathbf{b})$ & \\
\hline$(0.29,0.23,0.17)(0.70,0.81,0.86)$ & $(0.45,0.29,0.14)(0.55,0.55,0.70)$ & $(0.24,0.19,0.14)(0.83,0.90,0.90)$ \\
\hline
\end{tabular}

Now, we compute the distance measure of PIS and NIS to weighted normalized matrix as follows

Distance of PIS to weighted normalized matrix.

\begin{tabular}{|l|l|l|l|}
\hline 0.39499 & 0.22358 & 0.49942 & 0.23045 \\
\hline
\end{tabular}


and

Distance of PIS to weighted normalized matrix.

\begin{tabular}{|l|l|l|l|}
\hline 0.20218 & 0.12156 & 0.23259 & 0.20181 \\
\hline
\end{tabular}

Finally, the ranking of the alternative is

\begin{tabular}{|l|l|l|l|}
\hline 0.33856 & 0.35221 & 0.31774 & 0.46686 \\
\hline
\end{tabular}

Hence $\bar{A}_{3}$ alternative has the minimum distance, so it is the best alternative in the given list of alternatives. The comparison matrix is given in Table 8 .

Table 8. Comparison matrix.

\begin{tabular}{cc|c|c|c|c|c}
\hline & \multicolumn{4}{c}{ Revised Closeness Indices } & Ranking \\
\hline $\begin{array}{c}\text { Existing } \\
\text { Technique [18] } \\
\begin{array}{c}\text { Propose } \\
\text { Technique }\end{array}\end{array}$ & 0.33856 & 0.35221 & 0.31774 & 0.46686 & \multirow{2}{*}{$\bar{A}_{3}>\bar{A}_{1}>\bar{A}_{2}>\bar{A}_{4}$} \\
\cline { 2 - 5 } & 0.4278 & 0.5989 & 0.3317 & 0.4389 & 0.5902 & $\bar{A}_{3}>\bar{A}_{1}>\bar{A}_{4}>\bar{A}_{5}>\bar{A}_{2}$ \\
\cline { 2 - 4 } & & &
\end{tabular}

\section{Discussion}

We use the proposed PyPHF-TOPSIS method to find the best choice among the given alternatives. According to our proposed method the result is similar and $\bar{A}_{3}$ is the best alternative. This shows the proposed method is also applicable to IHFSs and more effective and rational. The proposed method is an extension of existing methods. The proposed method can be considered as an alternative to solve more realistic decision making problems. The existing method is different from the proposed method. It is clear that existing IHF decision making process is not applicable for group decision making and it does not work if weights are unknown. However, the proposed PyPHF-TOPSIS method is applicable for group decision making and also when the weights of DMs and criteria are fully unknown. The proposed method also studies probabilistic information for each hesitant membership value and nonmembership value so there is no loss of probabilistic information.

Consequently, the proposed procedure is more precise, feasible and active to solve MCDM problems with fully unidentified information among DMs as well as criteria.

\section{Conclusions}

In this manuscript, we have proposed a novel hybrid concept of Pythagorean probabilistic hesitant fuzzy set to tackle the random vagueness, which is an enhanced version of fuzzy set, IFS, PyFS and PHFS in decision making real life problems. Firstly, we introduced some basic operational laws to deal with the PyPHFNs. Then, we developed new generalized distance measures for PyPHFSs. Furthermore, we proposed aggregation operator using PyPHF information. The main benefit of the proposed operator is that it provides the probabilistic information to all Pythagorean hesitant positive and negative degrees which provide a good tool for the DM to make a decision efficiently. This developed operator has been applied to the MCDM problem using extended TOPSIS technique. To show the effectiveness and applicability of the proposed extended TOPSIS approach under PyPHF, information is illustrated by numerical example. A comparison analysis is also considered to authenticate the applicability of our proposed method in practical MADM problems. The main advantages of this manuscript are as follows:

(1) the TOPSIS method is generalized by PyPHFS with unidentified weight information

(2) the PyPHF-TOPSIS method is proposed to solve the PyPHF-MCGDM problems with entropy weight

(3) a case study for car allotment site selection is provided to show the proposed approach

(4) our proposed PyPHF-TOPSIS method makes the distance similarity degree from the positive and negative ideal solution with entropy weight prominent and 
(5) in this study, the TOPSIS method, which may be also a significant MADM or MAGDM method, has been considered to challenge ambiguous decision making problems.

In future research, considering the superiority of PyPHFSs, we can extend them to other methods, such as TODIM method, MABAC method, MULTIMOORA method, ORESTE method and so forth. In addition, we can propose some new weighting models to obtain attribute weights. In order to be able to apply these new methods better to actual decision making, we can use them to solve some medical diagnosis and risk investment problems.

Author Contributions: Conceptualization, S.A. (Saleem Abdullah); Funding acquisition, R.C.; Investigation, M.A.; Methodology, B.B. and S.A. (Shahzaib Ashraf); Project administration, R.C.; Software, S.A. (Shahzaib Ashraf); Supervision, S.A. (Saleem Abdullah) and R.C.; Writing —original draft, B.B. and S.A. (Shahzaib Ashraf); Writing - review \& editing, M.A., S.A. (Saleem Abdullah) and R.C. All authors have read and approved the final published version. All authors have read and agreed to the published version of the manuscript.

Funding: This research received no external funding.

Acknowledgments: This research was supported by Algebra and Applications Research Unit, Department of Mathematics and Statistics, Faculty of Science, Prince of Songkla University.

Conflicts of Interest: The authors declare no conflict of interest.

\section{References}

1. Li, C.; Zhu, Z. Research and application of a novel hybrid air quality early-warning system: A case study in China. Sci. Total. 2018, 626, 1421-1438. [CrossRef] [PubMed]

2. Chen, Z.; Cui, L.; Cui, X.; Li, X.; Yu, K.; Yue, K.; Dai, Z.; Zhou, J.; Jia, G.; Zhang, J. The association between high ambient air pollution exposure and respiratory health of young children: A cross sectional study in Jinan, China. Sci. Total. Environ. 2019, 656, 740-749. [CrossRef] [PubMed]

3. Zadeh, L.A. Fuzzy sets. Inf. Control. 1965, 8, 338-353. [CrossRef]

4. Atanassov, K. Intuitionistic fuzzy sets. Fuzzy Sets Syst. 1986, 20, 87-96. [CrossRef]

5. Chen, S.M.; Cheng, S.H.; Chiou, C.H. Fuzzy multiattribute group decision making based on intuitionistic fuzzy sets and evidential reasoning methodology. Inf. Fusion 2016, 27, 215-227. [CrossRef]

6. Yager, R.R.; Abbasov, A.M. Pythagorean membership grades, complex numbers, and decision making. Int. J. Intell. Syst. 2013, 28, 436-452. [CrossRef]

7. Yager, R.R. Pythagorean fuzzy subsets. In Proceedings of the 2013 joint IFSA World Congress and NAFIPS Annual Meeting (IFSA/NAFIPS), Edmonton, AB, Canada, 24-28 June 2013; pp. 57-61.

8. Yager, R.R. Pythagorean membership grades in multicriteria decision making. IEEE Trans. Fuzzy Syst. 2013, 22, 958-965. [CrossRef]

9. Torra, V. Hesitant fuzzy sets. Int. J. Intell. Syst. 2010, 25, 529-539 [CrossRef]

10. Khan, M.S.A.; Abdullah, S.; Ali, A.; Siddiqui, N.; Amin, F. Pythagorean hesitant fuzzy sets and their application to group decision making with incomplete weight information. J. Intell. Fuzzy Syst. 2017, 33, 3971-3985. [CrossRef]

11. Xu, Z.; Zhou, W. Consensus building with a group of decision makers under the hesitant probabilistic fuzzy environment. Fuzzy Optim. Decis. Mak. 2017, 16, 481-503. [CrossRef]

12. De Luca, A.; Termini, S. A definition of a nonprobabilistic entropy in the setting of fuzzy sets theory. Inf. Control 1972, 20, 301-312. [CrossRef]

13. Burillo, P.; Bustince, H. Entropy on intuitionistic fuzzy sets and on interval-valued fuzzy sets. Fuzzy Sets Syst. 1996, 78, 305-316. [CrossRef]

14. Szmidt, E.; Kacprzyk, J. Entropy for intuitionistic fuzzy sets. Fuzzy Sets Syst. 2001, 118, 467-477. [CrossRef]

15. Szmidt, E.; Baldwin, J. Entropy for intuitionistic fuzzy set theory and mass assignment theory. Notes Ifss 2004, 10, 15-28.

16. Hung, W.L.; Yang, M.S. Fuzzy entropy on intuitionistic fuzzy sets. Int. J. Intell. Syst. 2006, 21, 443-451. [CrossRef]

17. Xu, Z. Intuitionistic fuzzy aggregation operators. IEEE Trans. Fuzzy Syst. 2007, 15, 1179-1187.

18. Wang, H.; Li, D. Decision making with distance and cosine similarity measures for intuitionistic hesitant fuzzy sets. Ann. Fuzzy Math. Inform. 2017, 13, 729-742. [CrossRef] 
19. Garg, H. A new generalized improved score function of interval-valued intuitionistic fuzzy sets and applications in expert systems. Appl. Soft Comput. 2016, 38, 988-999. [CrossRef]

20. Wei, G. Interval valued hesitant fuzzy uncertain linguistic aggregation operators in multiple attribute decision making. Int. J. Mach. Learn. Cybern. 2016, 7, 1093-1114. [CrossRef]

21. Kumar, K.; Garg, H. Connection number of set pair analysis based TOPSIS method on intuitionistic fuzzy sets and their application to decision making. Appl. Intell. 2018, 48, 2112-2119. [CrossRef]

22. Kumar, K.; Garg, H. Prioritized linguistic interval-valued aggregation operators and their applications in group decision-making problems. Mathematics 2018, 6, 209. [CrossRef]

23. Wang, P.; Wei, G.; Wang, J.; Lin, R.; Wei, Y. Dual hesitant q-Rung orthopair fuzzy hamacher aggregation operators and their applications in scheme selection of construction project. Symmetry 2019, 11, 771. [CrossRef]

24. Tang, X.; Wei, G.; Gao, H. Pythagorean fuzzy Muirhead mean operators in multiple attribute decision making for evaluating of emerging technology commercialization. Econ.-Res.-Ekon. istra živanja 2019, 32, 1667-1696. [CrossRef]

25. Gao, H. Pythagorean fuzzy Hamacher prioritized aggregation operators in multiple attribute decision making. J. Intell. Fuzzy Syst. 2018, 35, 2229-2245. [CrossRef]

26. Meng, F.; Chen, X. Correlation coefficients of hesitant fuzzy sets and their application based on fuzzy measures. Cogn. 2015, 7, 445-463. [CrossRef]

27. Garg, H. Hesitant Pythagorean fuzzy Maclaurin symmetric mean operators and its applications to multiattribute decision-making process. Int. J. Intell. Syst. 2019, 34, 601-626. [CrossRef]

28. Zhao, N.; Xu, Z.; Liu, F. Group decision making with dual hesitant fuzzy preference relations. Cogn. Comput. 2016, 8, 1119-1143. [CrossRef]

29. Farhadinia, B.; Xu, Z. Distance and aggregation-based methodologies for hesitant fuzzy decision making. Cogn. Comput. 2017, 9, 81-94. [CrossRef]

30. Arora, R.; Garg, H. A robust correlation coefficient measure of dual hesitant fuzzy soft sets and their application in decision making. Eng. Appl. Artif. Intell. 2018, 72, 80-92. [CrossRef]

31. Garg, H.; Arora, R. Distance and similarity measures for dual hesitant fuzzy soft sets and their applications in multicriteria decision making problem. Int. J. Uncertain. Quantif. 2017, 7. [CrossRef]

32. Wei, G.; Alsaadi, F.E.; Hayat, T.; Alsaedi, A. Hesitant fuzzy linguistic arithmetic aggregation operators in multiple attribute decision making. Iran. J. Fuzzy Syst. 2016, 13, 1-16.

33. Garg, H. Hesitant Pythagorean fuzzy sets and their aggregation operators in multiple attribute decision-making. Int. Uncertain. Quantif. 2018, 8. [CrossRef]

34. Garg, H.; Kumar, K. Group decision making approach based on possibility degree measure under linguistic interval-valued intuitionistic fuzzy set environment. J. Ind. Manag. 2018, 13, 1. [CrossRef]

35. Yue, Z. An avoiding information loss approach to group decision making. Appl. Math. Model. 2013, 37, 112-126. [CrossRef]

36. Zhang, X. A novel approach based on similarity measure for Pythagorean fuzzy multiple criteria group decision making. Int. Intell. Syst. 2016, 31, 593-611. [CrossRef]

37. Ren, P.; Xu, Z.; Gou, X. Pythagorean fuzzy TODIM approach to multi-criteria decision making. Appl. Soft Comput. 2016, 42, 246-259. [CrossRef]

38. Peng, X.; Yang, Y. Pythagorean fuzzy Choquet integral based MABAC method for multiple attribute group decision making. Int. J. Intell. Syst. 2016, 31, 989-1020. [CrossRef]

39. Zhang, X. Multicriteria Pythagorean fuzzy decision analysis: A hierarchical QUALIFLEX approach with the closeness index-based ranking methods. Inf. Sci. 2016, 330, 104-124. [CrossRef]

40. Peng, X.; Yuan, H.; Yang, Y. Pythagorean fuzzy information measures and their applications. Int. J. Intell. Syst. 2017, 32, 991-1029. [CrossRef]

41. Zhang, R.; Wang, J.; Zhu, X.; Xia, M.; Yu, M. Some generalized Pythagorean fuzzy Bonferroni mean aggregation operators with their application to multiattribute group decision-making. Complexity 2017, 2017, 5937376. [CrossRef]

42. Liang, D.; Xu, Z. The new extension of TOPSIS method for multiple criteria decision making with hesitant Pythagorean fuzzy sets. Appl. Soft Comput. 2017, 60, 167-179. [CrossRef]

43. Pérez-Domínguez, L.; Rodríguez-Picón, L.A.; Alvarado-Iniesta, A.; Luviano Cruz, D.; Xu, Z. MOORA under Pythagorean fuzzy set for multiple criteria decision making. Complexity 2018, 2018, 2602376 . [CrossRef] 
44. Xue, W.; Xu, Z.; Zhang, X.; Tian, X. Pythagorean fuzzy LINMAP method based on the entropy theory for railway project investment decision making. Int. J. Intell. Syst. 2018, 33, 93-125. [CrossRef]

45. Zhang, L.; Meng, F. An approach to interval-valued hesitant fuzzy multiattribute group decision making based on the generalized Shapley-Choquet integral. Complexity 2018, 2018, 3941847. [CrossRef]

46. Guleria, A.; Bajaj, R.K. Pythagorean Fuzzy-Norm Information Measure for Multicriteria Decision-Making Problem. Adv. Fuzzy Syst. 2018, 2018, 8023013. [CrossRef]

47. Yang, M.S.; Hussain, Z. Distance and similarity measures of hesitant fuzzy sets based on Hausdorff metric with applications to multi-criteria decision making and clustering. Soft Comput. 2019, 23, 5835-5848. [CrossRef]

48. Shannon, C.E. A mathematical theory of communication. Bell Syst. Technol. J. 1948, 27, 379-423. [CrossRef]

49. Hussain, Z.; Yang, M.S. Entropy for hesitant fuzzy sets based on Hausdorff metric with construction of hesitant fuzzy TOPSIS. Int. J. Fuzzy Syst. 2018, 20, 2517-2533. [CrossRef]

50. Hwang, C.L.; Yoon, K.S. Multiple Attribute Decision Methods and Applications; Springer: Berlin, German, 1981; pp. 673-674.

51. Chen, C.T. Extensions of the TOPSIS for group decision-making under fuzzy environment. Fuzzy Sets Syst. 2000, 114, 1-9. [CrossRef]

52. Boran, F.E.; Genç, S.; Kurt, M.; Akay, D. A multi-criteria intuitionistic fuzzy group decision making for supplier selection with TOPSIS method. Expert Syst. Appl. 2009, 36, 11363-11368. [CrossRef]

53. Chen, T.Y.; Tsao, C.Y. The interval-valued fuzzy TOPSIS method and experimental analysis. Fuzzy Sets Syst. 2008, 159, 1410-1428. [CrossRef]

54. Li, D.F. TOPSIS-based nonlinear-programming methodology for multiattribute decision making with interval-valued intuitionistic fuzzy sets. IEEE Trans. Fuzzy Syst. 2010, 18, 299-311. [CrossRef]

55. Park, J.H.; Park, I.Y.; Kwun, Y.C.; Tan, X. Extension of the TOPSIS method for decision making problems under interval-valued intuitionistic fuzzy environment. Appl. Math. 2011, 35, 2544-2556. [CrossRef]

56. Cables, E.; García-Cascales, M.S.; Lamata, M.T. The LTOPSIS: An alternative to TOPSIS decision-making approach for linguistic variables. Expert Syst. Appl. 2012, 39, 2119-2126. [CrossRef]

57. Xu, Z.; Zhang, X. Hesitant fuzzy multi-attribute decision making based on TOPSIS with incomplete weight information. Knowl.-Based Syst. 2013, 52, 53-64. [CrossRef]

58. Beg, I.; Rashid, T. TOPSIS for hesitant fuzzy linguistic term sets. Int. J. Intell. Syst. 2013, 28, 1162-1171. [CrossRef]

59. Khan, A.A.; Ashraf, S.; Abdullah, S.; Qiyas, M.; Luo, J.; Khan, S.U. Pythagorean fuzzy Dombi aggregation operators and their application in decision support system. Symmetry 2019, 11, 383. [CrossRef]

60. Biswas, A.; Sarkar, B. Pythagorean fuzzy TOPSIS for multicriteria group decision-making with unknown weight information through entropy measure. Int. J. Intell. Syst. 2019, 34, 1108-1128. [CrossRef]

61. Barukab, O.; Abdullah, S.; Ashraf, S.; Arif, M.; Khan, S.A. A New Approach to Fuzzy TOPSIS Method Based on Entropy Measure under Spherical Fuzzy Information. Entropy 2019, 21, 1231. [CrossRef]

62. Baloglu, U.B.; Demir, Y. An Agent-Based Pythagorean Fuzzy Approach for Demand Analysis with Incomplete Information. Int. J. Intell. Syst. 2018, 33, 983-997. [CrossRef]

63. Zhang, Z.M. Deriving the priority weights from incomplete hesitant fuzzy preference relations based on multiplicative consistency. Appl. Soft Comput. 2016, 46, 37-59. [CrossRef]

(C) 2020 by the authors. Licensee MDPI, Basel, Switzerland. This article is an open access article distributed under the terms and conditions of the Creative Commons Attribution (CC BY) license (http://creativecommons.org/licenses/by/4.0/). 